\title{
PARTNER REPUTATION AND ITS EFFECT ON RESOURCE ACQUISITION IN ENTREPRENEURIAL COMPANIES
}

\author{
TOM VANACKER \\ Department of Accounting \& Corporate Finance \\ Ghent University \\ Kuiperskaai 55E, 9000 Gent, Belgium
}

\begin{abstract}
The general perspective in reputational scholarship is that all aspects of reputation matter. Longitudinal data on human and financial resource mobilization in 94 entrepreneurial companies after investment relationship formation with venture capital investors indicate that different aspects of investment partner reputation matter for subsequent resource mobilization from different parties.
\end{abstract}

\section{INTRODUCTION}

The lack of established working relationships, social approval, tested routines and the resulting high risk of failure make resource mobilization a key challenge and a process fraught with difficulties, especially within young and small entrepreneurial companies (Stinchcombe, 1965; Aldrich \& Auster, 1986). Interorganizational relationships with more established firms have become an attractive way to obtain resources (Baum, Calabrese, \& Silverman, 2000). This study focuses on investment relationships formed between venture capital firms and entrepreneurial companies. These are typically one of the earliest and most critical relationships formed by young companies with high growth potential requiring quick access to a variety of resources (Hallen, 2008). Investment relationships with venture capitalists not only allow access to vital resources, but also act as powerful signals that communicate the quality of entrepreneurial companies to external markets, which is expected to facilitate subsequent resource mobilization (Stuart, Hoang, \& Hybels, 1999; Stuart, 2000; Davila, Foster, \& Gupta, 2003; Janney \& Folta, 2003). Not all investment partners are equally valuable, however, and especially the most reputable investment partners will provide the strongest signals of company quality to external markets (Stuart et al., 1999; Janney \& Folta, 2006; Hallen, 2008).

A critical question is who these most reputable partners are, as reputation involves a different array of dimensions (Fombrun \& Shanley, 1990; Rindova, Williamson, Petkova, \& Sever, 2005; Rhee \& Valdez, 2009). We draw on recent reputation research, which indicates that reputation can be conceptualized as comprising two distinct dimensions (Rindova et al., 2005). One dimension reflects the degree to which stakeholders evaluate a firm positively on specific attributes, such as its expected ability based on past experience (Weigelt \& Camerer, 1988; Hsu, 2004; Janney \& Folta, 2006). The second dimension concerns firm prominence or the collective awareness and recognition gained by a firm through social influence in its organizational field (Rao, 1994; Rindova \& Fombrun, 1999; Pollock \& Rindova, 2003). We study how these different components of reputation matter for resource mobilization in entrepreneurial companies.

More significantly, the implicit assumption in most research has been that different types of resource providers interpret signals in the same way. Empirical studies have often focused on 
the mobilization of one particular resource (Stuart et al., 1999; Davila et al., 2003; Janney \& Folta, 2003). We focus on the mobilization of two critical resources, namely human and financial resources. Entrepreneurial companies with high growth ambitions need to mobilize resources from multiple stakeholder groups which exhibit fundamentally different characteristics. The characteristics of the stakeholder groups may influence signal interpretation and hence different types of stakeholders may interpret the same signal differently (Heil \& Robertson, 1991). This implies that different types of stakeholders may focus on different dimensions of investment partner reputation (Rhee \& Valdez, 2009). Our study is one of the first empirical studies illuminating how distinct dimensions of reputation are attended to by different types of stakeholders. This is of significant theoretical interest and may inform reputation researchers on the fundamental question whether companies have one or multiple reputations (Fombrun $\&$ Shanley, 1990; Rindova et al., 2005).

\section{THEORY DEVELOPMENT}

A first dimension of reputation focuses on how stakeholders evaluate a firm positively based on previous actions and strategic decisions (Rindova et al., 2005). In accord with this definition of reputation, Hsu (2004) indicates that within the venture capital context reputation is primarily based on previous investment experience. More in particular, the accumulated experience within an industrial sector is expected to serve as a powerful contributor to venture capital firm reputation (Hsu, 2004; Janney \& Folta, 2006). There are several reasons why stakeholders will perceive venture capital firms with more relevant investment experience as more capable. The experience of investment partners is likely to influence both their ability to select the most promising companies and to influence company development after the initial investment through the provision of superior value added services (Dimov \& Shepherd, 2005; Dimov \& De Clercq, 2006; Sorensen, 2007). So when companies are able to affiliate with more experienced investment partners this is expected to decrease the uncertainty characterizing entrepreneurial companies which in turn is expected to increase the willingness of outsiders to contribute resources (Janney \& Folta, 2006). This leads to the following hypothesis:

Hypothesis 1. The industry-specific experience of the initial venture capital investor will allow companies to mobilize more resources over time.

A second dimension of reputation is prominence and focuses on how well-known a firm is within its organizational field (Rindova et al., 2005). When entrepreneurial companies affiliate with well-known investment partners this is likely to have at least two effects. First, it will draw attention to entrepreneurial companies. Once resource providers have learned about the existence of companies, because they affiliate with well-known partners in the entrepreneurship community, companies are more likely to become part of the "consideration set" of resource providers (Merton, 1987; Jensen \& Roy, 2008). This is important as potential resource providers are only likely to transact with and contribute resources to companies they have at least heard of (Merton, 1987).

Second, prominent venture capital firms are expected to have access to many investment opportunities. This is because entrepreneurs need to put their companies forward as candidates for receiving finance before investors can select the companies in which they will invest (Eckhardt, Shane, \& Delmar, 2006). Well-known investors are likely to receive many investment 
proposals because of their visibility. Nevertheless, venture capital firms only decide to invest in few companies each year. Hence, the mere fact that entrepreneurial companies are able to raise finance from prominent investors will offer quality signals to resources providers (Stuart et al., 1999). This should make resource providers even more likely to transact with companies. The above arguments lead to the following hypothesis:

Hypothesis 2. The prominence of the initial venture capital investor will allow companies to mobilize more resources over time.

In line with the general perspective in reputational scholarship the above hypotheses indicate that all aspects of reputation are important. It is assumed that partner experience and partner prominence will benefit resource mobilization in entrepreneurial companies and this irrespective of the type of stakeholder from which resources are mobilized. Hence, all stakeholders interpret signals in the same way. In this paper, we propose that that different aspects of reputation have varying degrees of importance to different stakeholders, depending upon their knowledge of the organizational field in which the venture capital investor operates.

Prospective investors are a good example of stakeholders that will have deep knowledge about the venture capital industry, including the past actions of their peers and the companies in which they invested. The expected ability of an initial venture capital firm based on previous investment experience may be relatively easy to assess for other investors. Moreover, prospective investors are likely to recognize that the previous relevant investment experience of the initial investors is critical for the subsequent development of entrepreneurial companies. After all, the initial lead investor plays a key role in venture development through its presence in the board of directors (Lerner, 1995) and the contribution of knowledge-based resources (Sapienza, Manigart, \& Vermeir, 1996). However, initial investors may not only facilitate, but also hamper portfolio company development, for instance, by offering the wrong strategic recommendations or by imposing misguided constraints (Steier \& Greenwood, 1995). Potential investors perceive these risks as more limited when investors have accumulated relevant experience through previous investments in similar companies (Baeyens, Vanacker, \& Manigart, 2006). Hence, although new investors will almost always conduct their own extensive due diligence their investment decision is likely to be influenced by the industry-specific experience of the initial investor.

Not all stakeholders will have deep knowledge on the venture capital industry. Prior research demonstrates how entrepreneurs of technology-based companies generally have limited knowledge on how venture capital firms operate (Van Auken, 2001). It is reasonable to expect the average employee within an entrepreneurial company will experience the same problems. Employees are a good example of stakeholders that will have less knowledge on the venture capital industry. Due to their lack of knowledge, employees are expected to experience significant problems in assessing the quality of venture capital firms based on the previous experience of the latter. This leads to the following hypothesis:

Hypothesis 3. The industry-specific experience of the initial venture capital investor will be more important for companies to mobilize resources from investors compared to employees. 
While stakeholders with less knowledge on specific partners are expected to experience difficulties in assessing partner quality based on previous experiences, they may still rely on other signals to reduce uncertainty. One potential alternative is to focus on partner prominence, which by definition is easier to observe. When entrepreneurs team up with venture capital firms that are highly visible this will not only draw attention to the company (Jensen \& Roy, 2008), but may also influence the perception about company quality (Stuart et al., 1999). As such, the prominence of the initial lead investor may influence the decision of employees to join uncertain entrepreneurial companies. However, the effect of prominence may be less important when stakeholders already have deep knowledge on who their peers are and to which companies they have previously contributed resources. Wang (2009), for instance, demonstrates that venture capital investors are unlikely to invest in companies only because these companies have been introduced to them by a known source. This leads to the following hypothesis:

Hypothesis 4. The prominence of the initial venture capital investor will be more important for companies to mobilize resources from employees compared to investors.

\section{METHOD}

\section{Data Sources}

We use a database provided by the Belgian Venture Capital and Private Equity Association (B.V.A.) which relates venture capital backed companies to their lead investors. The dataset comprises 94 companies that received initial venture capital finance between 1999 and 2003. This is a random sample of about one third of the total number of initial investments by B.V.A. members over the timeframe of the study. Only initial investments conducted before the end of 2003 are included in order to have sufficient data to track resource mobilization in companies selected at the end of this timeframe. The dataset includes companies that eventually fail and hence results are not subject to survivorship bias.

Detailed yearly financial statement data is collected for each portfolio company from the year of initial venture capital investment up to five years after this investment. We hence construct a six-wave longitudinal dataset comprising 520 firm year observations. An important advantage of the Belgian setting is that all limited liability companies are required to file financial statements with the Belgian Central Bank. In order to collect data on the lead venture capital firm providing initial venture capital finance, multiple sources of data are used, including Zephyr, the B.V.A. database and trade directories. The lead venture capital firms providing initial finance range from small venture capital firms with only six million euro of assets under management to venture capital firms with more than one billion euro of assets under management.

\section{Measures}

We study the mobilization of human and financial resources from the year of investment relationship formation up to five years after the initial venture capital investment. Human resources reflect the number of employees in full time equivalents. Financial resources are operationalized as the amount of equity and financial debt outstanding. The mobilization of more resources is likely to be critical, as companies, which accumulate more resources early on, are 
likely to develop a sustainable competitive advantage over their resource-constrained peers (Lee, Lee, \& Pennings, 2001).

The key independent variables are correlates of venture capital firm experience and prominence measured at the year of the initial investment. Venture capital firm industry-specific experience is operationalized as the total number of investments made by the venture capital firm in the same industry (2-digit industry code) as the focal company before investing in this company (Gompers, Kovner, Lerner, \& Sharfstein, 2008). It represents cumulative industry experience and relates to the concept of venture capital firm reputation as perceived quality based on previous experience (Hsu, 2004; Janney \& Folta, 2006). The natural logarithm of industry experience is used as the value of each additional amount of investment experience is expected to be subject to decreasing returns (Pennings, Barkema, \& Douma, 1994).

Venture capital firm prominence is operationalized as the total number of media citations to particular venture capital firms in Belgian national newspapers in the period 1995 until the year of investment. The media presents stakeholders with information that affects the legitimization of firms (Pollock \& Rindova, 2003). We construct a simple count measure of media attention and do not attempt to categorize coverage as "good" or "bad". Cook, Kieschnick and Van Ness (2006), for instance, demonstrate how the media provides non-negative descriptive stories in over $99 \%$ of the articles they scrutinized in more detail. The natural logarithm of media citations is used in subsequent analyses.

We control of year and industry effects, company age at the time of the initial investment, company growth potential (proxied by the ratio of intangible assets to total assets), the amount of initial finance provided by the initial venture capital investors, syndication (the number of investors providing initial finance), venture capital investor type, venture capital investor size at the time of the initial investment (natural logarithm of capital under management) and venture capital investor age at the time of the initial investment.

\section{Model}

Random Coefficient Modeling (RCM) also referred to as mixed modeling or growth modeling is used as an appropriate longitudinal technique to study changes in the amount of human and financial resources mobilized over time. Many of the standard statistical techniques are not appropriate to use when data consist of repeated measures that are correlated within companies as this invalidates the basic assumption of independence. In order to deal with longitudinal data, scholars have often used general multivariate regressions models that require longitudinal data where all companies have the same number of repeated measures, taken at time points, which are also the same for all companies (Fitzmaurice, Laird, \& Ware, 2004). These strict assumptions are rarely fulfilled in longitudinal studies and are not required when using a RCM framework (Fitzmaurice et al, 2004). Moreover, the RCM framework allows modeling non-linear change and accounts for both individual differences between companies as well as similarities among groups of companies (Fitzmaurice et al., 2004). The RCM framework is gaining increasing attention by organizational scholars and recent applications in the organizational literature are available (Bliese \& Ployhart, 2002; Hausknecht, Hiller, \& Vance, 2008). 


\section{RESULTS AND IMPLICATIONS}

Results demonstrate the multidimensional nature of reputation and how different stakeholders are likely to focus on different dimensions of partner reputation before they contribute resources to uncertain entrepreneurial companies. While venture capital firm prominence is particularly important for portfolio companies to mobilize human resources, we fail to find an effect of the industry-specific experience of venture capital firms on the mobilization of human resources. Results are very different when we focus on the mobilization of financial resources. Here venture capital firm industry-specific experience plays a particularly important role, but we fail to find an effect of venture capital firm prominence on the mobilization of financial resources in portfolio companies. These results provides support for hypothesis 3 and 4.

A particular concern is self-selection which may bias our findings. Specifically, more reputable venture capital firms may select companies with higher growth potential or alternatively the most promising entrepreneurial companies may select the most reputable venture capital investors (Eckhardt et al., 2006; Sorensen, 2007). Failure to account for selection (possibly on unobservable characteristics) may lead to incorrect inferences with respect to the impact of venture capital firm reputation on company growth (Sorensen, 2007). However, we demonstrate how entrepreneurial companies backed by more reputable investors (both in terms of previous investment experience and prominence) do not exhibit higher growth in the years preceding the initial venture capital investor compared to companies backed by less reputable investors. Moreover, we ran selection models (including variables similar to Hsu (2004) such as the number of patents applied for before initial venture capital investment) and included inverse mills ratios in our models which did not alter our main conclusions. Overall, we provide consistent evidence that while self-selection is likely to occur, it is unlikely to fully explain the relationships between the different dimensions of investor reputation and resource mobilization in entrepreneurial companies.

The study makes several important contributions to reputation research. First, this is one of the first studies to address the impact of distinct dimensions of reputation on the mobilization of resources in entrepreneurial companies. Prior studies have focused on the impact of different dimensions of firm reputation on the ability of firms to demand a premium in order to affiliate with them (Rindova et al., 2005). The perspective in this study is different in that it focuses on the impact of partner reputation on the development of companies that affiliate with more or less reputable firms. Such a perspective is important as prior research indicates that accessing reputation is not for free (Fombrun \& Shanley, 1990; Hsu, 2004).

Second, this study addresses a long-standing debate in the reputation literature relating to the question whether a company has only one or multiple reputations (Fombrun \& Shanley, 1990; Rindova et al, 2005; Rhee \& Valdez, 2009). We demonstrate that reputation comprises distinct dimensions and that these different dimensions are attended to by different stakeholders. Results demonstrate how in the current research context partner experience is particularly important to mobilize financial resources while prominence is important to mobilize human resources. Nevertheless, experience and prominence are not fully orthogonal (Rindova et al., 2005) and hence partners may score high on the two dimensions. Overall, the results demonstrate a clear need to be explicit about the question from whose perspective reputation is studied.

\section{REFERENCES AVAILABLE FROM THE AUTHOR}

